\title{
Tolerance, bioavailability, and potential cognitive health implications of a distinct aqueous spearmint extract
}

\author{
Kristin M. Nieman ${ }^{1}$, Kristen D. Sanoshy ${ }^{1}$, Letizia Bresciani ${ }^{3}$, Arianne L. Schild ${ }^{1}$, Kathleen \\ M. Kelley ${ }^{1}$, Andrea L. Lawless ${ }^{1}$, Michael A. Ceddia ${ }^{2}$, Kevin C. Maki ${ }^{1}$, Daniele Del Rio ${ }^{3}$, \\ Kelli A. Herrlinger ${ }^{2}$
}

${ }^{1}$ Biofortis Clinical Research, 211 E. Lake St., Addison, IL, 60101, USA; ${ }^{2}$ Kemin Human Nutrition and Health, Kemin Foods, LC, 2100 Maury St., Des Moines, IA, 50317, USA; ${ }^{3}$ The Laboratory of Phytochemicals in Physiology, LS9 Bioactives and Health, Interlab Group, Department of Food Science, University of Parma, Parma, Italy

Corresponding author: Kelli A. Herrlinger, Kemin Human Nutrition and Health, 2100 Maury St., Des Moines, IA 50317, USA

Submission date: April 30, 2015; Acceptance date: May 28, 2015: Publication date: May 30, 2015

\begin{abstract}
Background: Cognitive function can decline during the aging process and significantly reduce quality of life. Although a number of interventions have been investigated for cognitive dysfunction, including antioxidants, this prominent health concern warrants further exploration of additional methods to support cognitive health later in life. An aqueous extract from a proprietary spearmint line has been developed which contains a number of antioxidant compounds, including rosmarinic acid, at higher levels than typically found in commerciallybred spearmint. Therefore, this pilot trial assessed the tolerance, bioavailability, and potential cognitive health implications of a proprietary spearmint extract in men and women with selfreported memory impairment.
\end{abstract}

Methods: Subjects consumed $900 \mathrm{mg} /$ day spearmint extract for 30 days. The sample population $(\mathrm{N}=11)$ was $73 \%$ female and $27 \%$ male with a mean age of $58.7 \pm 1.6 \mathrm{y}$. Tolerability parameters were assessed at baseline and end of treatment visits. Computerized cognitive function tests were completed and blood was drawn at pre- and post-dose $(0.5$ to $4 \mathrm{~h})$ timepoints during baseline and end of treatment visits. Subjective cognition was also assessed at the end of treatment.

Results: Neither serious adverse events nor clinically relevant findings were observed in any tolerability parameters. Plasma vanillic, caffeic, and ferulic acid sulfates, rosmarinic acid, and methyl rosmarinic acid glucuronide were detected in plasma following acute administration of the spearmint extract. Computerized cognitive function scores improved in reasoning $(\mathrm{P}=$ 
$0.023)$ and attention/concentration $(P=0.002)$ after 30 days of supplementation. After acute administration, subjects had improved attention/concentration in two tests at $2(\mathrm{P}=0.042$ and $\mathrm{P}$ $=0.025)$ and $4 \mathrm{~h}(\mathrm{P}=0.001$ and $\mathrm{P}=0.002)$.

Conclusions: The results from this pilot trial suggest that the spearmint extract, which contains higher rosmarinic acid content relative to extracts from typical commercial lines, was welltolerated at $900 \mathrm{mg} / \mathrm{day}$. The extract was also bioavailable. Further investigation is warranted regarding its potential for supporting cognitive health.

\section{BACKGROUND}

Cognitive function may decline in healthy individuals between early and late adulthood, as a natural part of the aging process. The prevalence of subjective memory impairment in older patients in community-based populations is reported with a large range of variation (11-50\%) [1, 2]. For example, in a cross-sectional study of 21,024 adults 50 years of age or older, $20 \%$ of participants self-reported memory impairment [3]. Another cross-sectional study evaluating 17 general practice clinics including 2,934 patients aged 65 and older reported that $23 \%$ of elderly patients surveyed self-reported memory impairment upon prompting; however, only $18 \%$ of those elderly patients who self-reported memory impairment consulted a physician for their impairment [4]. Although cognitive decline is generally accepted as a typical consequence of aging, it significantly decreases quality of life [5]. Roughly 5.4 million elderly Americans are estimated to have cognitive impairment without dementia and $12 \%$ of these individuals will develop dementia annually [6]. Although a number of treatments are available for more advanced stages of cognitive dysfunction, including dementia, there is a need to explore novel methods which can prevent or slow age-associated decline in cognitive function.

Throughout the ages, traditional medicine has used plant-based remedies to treat a number of ailments. More recently, plant-based dietary interventions such as ginkgo biloba, ginseng, and guarana have been investigated in clinical trials for their potential to enhance cognitive function in healthy volunteers [7-10]. Results from several trials have suggested that consumption of plant extracts within the Lamiaceae family may promote cognitive function in healthy volunteers [11-13]. However, randomized controlled trials specifically investigating the effects of aqueous spearmint (Mentha spicata L.) extracts, a member of the Lamiaceae family, on cognitive function are limited. A few studies have been conducted evaluating the effects of small quantities of spearmint oil in spearmint chewing gum on memory in healthy volunteers, which report conflicting results [14-16]. Previous work in rodents with an aqueous spearmint extract found that 320 and $640 \mathrm{mg} / \mathrm{kg}$ body weight of the extract (16 and $32 \mathrm{mg}$ rosmarinic acid/ $/ \mathrm{kg}$ body weight), equivalent to $600-1200 \mathrm{mg}$ of the spearmint extract on average for humans, were effective in improving memory and learning in a SAMP8 mouse model of accelerated aging [17, $18]$.

There are several published studies which have investigated the tolerance of consuming aqueous plant extracts within the Lamiaceae family; however a majority of these have investigated peppermint (Mentha Piperita) extracts, rather than spearmint extracts [19]. Preclinical safety studies were conducted on the spearmint extract used in this trial in accordance 
with the Organisation for Economic Cooperation and Development and the U.S. Food and Drug Administration's Redbook 2000 guidelines [20, 21]. Genotoxicity testing results demonstrated that the spearmint extract was non-mutagenic at concentrations up to $5000 \mu \mathrm{g} / \mathrm{plate}$, as assessed by the Ames bacterial reverse mutation assay. Additionally, the extract was non-clastogenic at dose levels up to $5000 \mu \mathrm{g} / \mathrm{ml}$ using the chromosomal aberration assay [22]. A 90-day toxicity study in rodents determined the No Observed Adverse Effect Level (NOAEL) to be $1948 \mathrm{mg} / \mathrm{kg}$ body weight/day of the spearmint extract, which corresponds to $300 \mathrm{mg}$ rosmarinic acid/kg body weight/day [22].

Spearmint extracts are widely used as flavorings and seasonings in beverages and confectioneries and have Generally Recognized as Safe (GRAS) status as a natural seasoning/flavoring, essential oil, and natural extract in the United States [23, 24]. However, spearmint extract would have to be consumed at doses higher than what would typically be found in flavorings and seasonings when taken for cognitive benefit. Therefore, the objective of this pilot study was to evaluate the tolerability and bioavailability of a proprietary aqueous spearmint extract when consumed at $900 \mathrm{mg}$, and to identify its potential effects on cognitive function in healthy men and women with self-reported memory impairment.

\section{METHODS}

\section{Chemicals}

All chemicals and solvents were of analytical grade. Rosmarinic acid was purchased from Sigma-Aldrich Co. (St. Louis, MO, USA), whereas ferulic acid-4- $O$-sulfate and dihydrocaffeic acid 3-O-sulfate were purchased from TRC - Toronto Research Chemicals (Toronto, Ontario, Canada). All solvents and reagents were purchased from Carlo Erba Reagents (Milano, Italy).

\section{Study Design}

This open-label, pilot study was conducted in accordance with Good Clinical Practice Guidelines, the Declaration of Helsinki [25], and the United States 21 Code of Federal Regulations [26]. An appropriately constituted Institutional Review Board (Hummingbird IRB, Cambridge, MA) approved the study protocol and informed consent documents prior to initiation of the study [25]. This study included one telephone screen, one screening visit, and two treatment visits occurring at the beginning and end of a 30-day treatment period. Signed informed consent and authorization for disclosure of protected health information forms were provided by the subjects prior to implementing any protocol-specific procedures. Subjects were informed of their right to withdraw from the study at any time.

\section{Subjects}

Generally healthy men and women 50-70 years of age, with body mass index between 18.5-35.0 $\mathrm{kg} / \mathrm{m}^{2}$, and possessing a high school diploma were recruited for this trial. Subjects were eligible for the trial if they reported gradual memory impairment by scoring $\geq 25$ on the Memory Assessment Clinic Scale Questionnaire (MAC-Q), administered during the telephone screen [27, 28]. Eligible subjects were also required to exhibit normal cognitive function during the screening visit, as measured by a score of $\geq 24$ on the Mini Mental State Examination (MMSE) $[28,29]$. 
Eligible subjects also included individuals who were willing to maintain their habitual diet (including caffeinated and alcoholic beverages) and exercise routines throughout the study period, in addition to refraining from tobacco products $(1 \mathrm{~h})$, caffeine $(10-14 \mathrm{~h})$, alcohol $(24 \mathrm{~h})$, and vigorous exercise $(24 \mathrm{~h})$ prior to and during the test visits, as indicated by the time in parentheses.

Subjects were deemed ineligible for participation in the study based on the following exclusion criteria: uncontrolled hypertension (systolic blood pressure $\geq 160 \mathrm{~mm} \mathrm{Hg}$ or diastolic blood pressure $\geq 100 \mathrm{~mm} \mathrm{Hg}$ ); abnormal laboratory test results of clinical significance (at the discretion of the Investigator); a history or presence of clinically important cardiac (including coronary heart disease), renal, hepatic, endocrine (including type 1 or type 2 diabetes mellitus), pulmonary, biliary, gastrointestinal, pancreatic, or neurologic disorders (including sleep disorders, head injuries, Alzheimer's disease, Parkinson's disease, stroke, inflammatory brain disease); a recent history or presence of cancer, with the exception of non-melanoma skin cancer; history within 12 months of screening or strong potential for alcohol (>14 servings/week) or substance abuse; history of depression within 24 months of screening; history of heavy smoking (>1 pack/day) within 3 months of screening; history of heavy caffeinated beverage consumption (>400 mg caffeine/day) within 2 weeks of screening; and history of use of psychotropic medications within one month of screening. Females who were pregnant, lactating, or planning to be pregnant during the study period, in addition to those with childbearing potential who were unwilling to commit to the use of a medically approved form of contraception were not enrolled. Individuals who reported occupations that resulted in disruption of sleep-wake cycles were also excluded from the study. If a deviation $( \pm 2 \mathrm{~h})$ in the participants' normal sleep duration occurred the evening before a test visit, the visit was rescheduled. Additionally, individuals were excluded if use of medications or supplements known to alter cognitive function was reported within two weeks of screening. If an infection occurred during the study or a participant used antibiotics within 5 days of any visit, clinic visits were rescheduled to allow at least five days for resolution of the infection or completion of the antibiotic therapy. Finally, subjects were excluded from the study if they were unable to complete or understand the cognitive function practice tests during screening.

\section{Study Product and Treatment}

The proprietary aqueous spearmint extract (Neumentix ${ }^{\mathrm{TM}}$ Phenolic Complex K110-42) [30] was manufactured by Kemin Foods, L.C. (Des Moines, IA) and packaged in $450 \mathrm{mg}$ capsules by Five-Star Pharmacy (Clive, IA). The spearmint extract contained $15.2 \%$ rosmarinic acid, in addition to a number of other classes of phenolic compounds including salvianolic, caffeoylquinic, and hydroxphenylpropanoic acids (Mena, Del Rio, et al. manuscript in preparation). Subjects were instructed to consume $900 \mathrm{mg}$ ( 2 capsules) of the extract daily with breakfast. Compliance with study product consumption was evaluated by the study staff according to the returned quantity of study product and a study product diary that subjects completed daily. Compliance was calculated as a percentage of study product consumed. 


\section{Tolerability Assessments}

Fasting (10-14 h) blood samples were collected at screening and the end of the treatment period, prior to the acute administration test for plasma chemistry, whole blood hematology, and plasma lipid profiles. Blood assessments were completed by Elmhurst Memorial Reference Laboratory (Elmhurst, IL). Plasma glucose concentrations were assessed using the glucose oxidase method. The plasma lipid profile assessment included total cholesterol (TC), high-density lipoprotein cholesterol (HDL-C), and triglycerides (TG), and was analyzed using the Beckman Coulter's LX20 PRO (Fullerton, CA, USA), as previously described by the Standardization Program of the Centers for Disease Control and Prevention and the National Heart, Lung, and Blood Institute [31]. The Friedewald equation was used to estimate LDL-C concentrations in $\mathrm{mg} / \mathrm{dL}$ as follows: LDL-C $=$ TC - HDL-C - TG/5. Non-HDL-C was calculated as non-HDL-C $=$ TC - HDL-C [32]. Vital signs (seated, resting blood pressure/heart rate) were measured twice and averaged, using an automated device, at baseline and at the end of the treatment period. Adverse events were also assessed at baseline and at the end of the treatment period, both at the beginning and end of each test visit.

A gastrointestinal (GI) tolerability questionnaire was administered at each test visit prior to test product consumption, as described previously with minor modifications [33]. Subjects were instructed to recall their GI symptoms over the last 30 days and rank them as follows: less than usual (-2), somewhat less than usual (-1), usual/not experienced (0), somewhat more than usual (1), and much more than usual (2). A composite score was also calculated for all ratings $\geq 0$ (somewhat more than usual).

\section{Plasma Extraction and uHPLC-MSn Analysis}

Plasma samples were extracted as previously reported [34]. Two $0.5 \mathrm{~mL}$ aliquots of plasma were extracted with $1.25 \mathrm{~mL}$ of acetonitrile, after vortexing for $5 \mathrm{~min}$. Samples were centrifuged for $10 \mathrm{~min}$ at $14000 \mathrm{rpm}$ and $1.5 \mathrm{~mL}$ supernatant was dried under vacuum by rotary evaporation. The pellet was dissolved in $100 \mu \mathrm{L}$ of $80 \%$ methanol in $0.1 \%$ formic acid-acidified water (v/v) and stored at $-80{ }^{\circ} \mathrm{C}$ until analysis by ultra-high performance liquid chromatography coupled with tandem mass spectrometry (uHPLC-MSn).

An Accela ${ }^{\mathrm{TM}}$ uHPLC 1250 apparatus equipped with the LTQ XL ${ }^{\mathrm{TM}}$ Linear Ion Trap Mass Spectrometer (LITMS) fitted with a heated-ESI (H-ESI-II) probe (Thermo Fisher Scientific Inc., San Jose, CA, USA) was used for the analysis. Separations were carried out by a Kinetex PFP (50 x $2.1 \mathrm{~mm}), 2.6 \mathrm{~mm}$ particle size (Phenomenex, Torrance, CA, USA). Phenolic metabolites were detected in negative ionization mode, with mobile phase, pumped at a flow-rate of 0.3 $\mathrm{mL} / \mathrm{min}$, consisting of a mixture of acidified acetonitrile $(0.1 \%$ formic acid; solvent $\mathrm{A})$ and $0.1 \%$ aqueous formic acid (solvent B). Following $1 \mathrm{~min}$ of $2 \%$ solvent $\mathrm{A}$ in $\mathrm{B}$, the proportion of $\mathrm{A}$ increased linearly to $35 \%$ over a period of $10 \mathrm{~min}$. The H-ESI-II interface was set to a capillary temperature of $275{ }^{\circ} \mathrm{C}$ and the source heater temperature was $50{ }^{\circ} \mathrm{C}$. The sheath gas $\left(\mathrm{N}_{2}\right)$ flow rate was set at 40 (arbitrary units) and the auxiliary gas $\left(\mathrm{N}_{2}\right)$ flow rate at 5 (arbitrary units). During analysis, the source voltage was $4 \mathrm{kV}$, and the capillary voltage and tube lens voltage were $-26.0 \mathrm{~V}$ and $-77.7 \mathrm{~V}$, respectively.

Initially, preliminary analysis of $5 \mu \mathrm{L}$ of plasma extract was carried out using full-scan, datadependent $\mathrm{MS}^{3}$, scanning from a mass to charge $(\mathrm{m} / \mathrm{z})$ of 100 to 800 using a collision-induced 
dissociation (CID) equal to 35 (arbitrary units) to obtain fragmentation. After this first step, further specific selected reaction monitoring (SRM) analyses were carried out to unambiguously identify and quantify the detected metabolites, by monitoring specific $\mathrm{m} / \mathrm{z}$ transitions: $163 \rightarrow 119$ (coumaric acid), 179 $\rightarrow 135$ (caffeic acid), 193 $\rightarrow 134,149,178$ (ferulic acid), $247 \rightarrow 147$ (vanillic acid sulfate), $259 \rightarrow 179$ (caffeic acid sulfate), $261 \rightarrow 181$ (dihydrocaffeic acid sulfate), $273 \rightarrow 193$ (ferulic acid sulfate), 275 $\rightarrow 195$ (dihydroferulic acid sulfate), 359 $\rightarrow 161,179,197$ (rosmarinic acid), $369 \rightarrow 193$ (ferulic acid glucuronide), 439 $\rightarrow 359$ (rosmarinic acid sulfate), 535 $\rightarrow 359$ (rosmarinic acid glucuronide), $549 \rightarrow 373$ (methyl rosmarinic acid glucuronide). Molecules were fragmented using pure helium (99.99\%), with a CID setting of 25, to obtain the fragmentation of the molecular ion. Identified metabolites were quantified as ferulic acid-4- $O$-sulfate, dihydrocaffeic acid 3-O-sulfate and rosmarinic acid equivalents by using calibration curves ranging from 1 to $1000 \mathrm{nmol} / \mathrm{L}$. Specifically, vanillic acid sulfate, caffeic acid sulfate, ferulic acid sulfate and dihydroferulic acid sulfate were quantified as ferulic acid-4- $O$-sulfate equivalents, with dihydrocaffeic acid sulfate also being expressed as dihydrocaffeic acid 3-Osulfate equivalents. Rosmarinic acid and methyl rosmarinic acid glucuronide were quantified as rosmarinic acid equivalents.

\section{Cognitive Function Assessments}

A battery of publicly available computerized brain training tasks (http://www.cambridgebrainsciences.com) was used to assess cognitive function (Cambridge Brain Sciences, London, Ontario, Canada). These tasks were designed using established cognitive neuroscience paradigms in parallel forms to assess memory, reasoning, attention/concentration, and planning, as previously described [35]. The battery included eight tasks which are summarized in Table 1: digit span (memory 1), paired associates (memory 2), double trouble (reasoning 1), odd one out (reasoning 2), rotations (attention/concentration 1), polygons (attention/concentration 2), spatial search (planning 1), and spatial slider (planning 2). Subjects completed a practice session during the screening visit to gain familiarity with the tests, to limit training effects and variability in test scores, and to ensure an optimal level of performance. The practice sessions included two complete test batteries separated by at least one hour. The battery was administered at $-1,2.25$, and $4 \mathrm{~h}$, where $\mathrm{t}=0 \mathrm{~h}$ was the study product/breakfast consumption at baseline and end of treatment. Each battery took approximately 30-45 min and was completed in an environment where temperature, lighting, and noise were kept constant.

The Subject Global Impression (SGI) Scale of Cognition questionnaire was administered at the end of the 30-day supplementation period to assess subjective cognition [28]. Subjects were instructed to rate their memory, attention, and speed of thinking at the end of the study relative to their condition prior to inclusion in the study as follows: very much improved (1), much improved (2), minimally improved (3), no change (4), minimally worse (5), much worse (6), and very much worse (7). A composite score was calculated as the average of the three domains (memory, attention, and speed of thinking). The difference from 'no change' (4) was calculated for each domain and the composite score. 
Table 1. Overview of the cognitive function test battery ${ }^{1}$

\begin{tabular}{|c|c|c|c|}
\hline Task & $\begin{array}{l}\text { Domain/ } \\
\text { Designation }\end{array}$ & Brief Description & Outcome Measure \\
\hline Digit span & Memory 1 & $\begin{array}{l}\text { A sequence of numbers is presented for the subject to } \\
\text { remember and recall. The test ends when three errors } \\
\text { are made. }\end{array}$ & $\begin{array}{l}\text { Maximum level } \\
\text { achieved (maximum } \\
\text { level }=25 \text { ) }\end{array}$ \\
\hline $\begin{array}{l}\text { Paired } \\
\text { associates }\end{array}$ & Memory 2 & $\begin{array}{l}\text { The subject recalls an object and the location it } \\
\text { appeared in. The test ends when three errors are } \\
\text { made. }\end{array}$ & $\begin{array}{l}\text { Maximum level } \\
\text { achieved (maximum } \\
\text { level }=24 \text { ) }\end{array}$ \\
\hline $\begin{array}{l}\text { Double } \\
\text { trouble }\end{array}$ & Reasoning 1 & $\begin{array}{l}\text { The subject determines the word at the bottom of the } \\
\text { screen that describes the color of the ink of the word } \\
\text { at the top of the screen. The subject solves as many } \\
\text { problems as possible in } 1.5 \text { min. }\end{array}$ & Total score \\
\hline Odd one out & Reasoning 2 & $\begin{array}{l}\text { The subject determines which pattern does not match } \\
\text { the other patterns on the screen. The subject solves as } \\
\text { many problems as possible in } 3 \text { min. }\end{array}$ & Total score \\
\hline Rotations & $\begin{array}{l}\text { Attention/ } \\
\text { Concentration } 1\end{array}$ & $\begin{array}{l}\text { The subject decides if rotating one shape would result } \\
\text { in it matching the other shape on the screen. The } \\
\text { subject solves as many problems as possible in } 1.5 \\
\text { min. }\end{array}$ & Total score \\
\hline Polygons & $\begin{array}{l}\text { Attention/ } \\
\text { Concentration } 2\end{array}$ & $\begin{array}{l}\text { The subject decides if a single shape is identical to } \\
\text { one of two overlapping shapes. The subject solves as } \\
\text { many problems as possible in } 1.5 \mathrm{~min} \text {. }\end{array}$ & Total score \\
\hline $\begin{array}{l}\text { Spatial } \\
\text { search }\end{array}$ & Planning 1 & $\begin{array}{l}\text { The subject must find hidden tokens, remember where } \\
\text { the tokens are hidden, and identify tokens in each box } \\
\text { without clicking on the previously identified tokens. } \\
\text { The test ends when three errors are made. }\end{array}$ & $\begin{array}{l}\text { Maximum level } \\
\text { achieved (maximum } \\
\text { level }=25 \text { ) }\end{array}$ \\
\hline $\begin{array}{l}\text { Spatial } \\
\text { slider }\end{array}$ & Planning 2 & $\begin{array}{l}\text { The subject must rearrange numbered tiles in order by } \\
\text { dragging them in and out of opens spaces in as few of } \\
\text { moves as possible. The subject solves as many } \\
\text { problems as possible in } 3 \text { min. }\end{array}$ & Total score \\
\hline
\end{tabular}

${ }^{1}$ The cognitive function test battery included eight publicly available (http://www.cambridgebrainsciences.com) tasks (Cambridge Brain Sciences, London, Ontario, Canada).

All tests of significance in this pilot study were performed at alpha $<0.1$, two-sided in this exploratory pilot trial. P-values were calculated using a paired t-test if the data were normally distributed, or the Wilcoxon sign-rank test if the normality assumption was rejected at the $1 \%$ level with the Shapiro-Wilk test [36]. Statistical analyses for safety measures were completed on data collected from all subjects who were randomized and had consumed at least one dose of study product. The analyses of outcomes were completed on a modified intention-to-treat (MITT) sample. The MITT sample included all subjects who provided at least one postrandomization outcome data point during the treatment. Additionally, a per-protocol (PP) sample comprised a subset of the MITT population. Subjects were excluded from the PP sample for violations of inclusion/exclusion criteria and non-compliance including: missing appointments, $<80 \%$ or $>120 \%$ compliance with study product consumption, or failure to consume the entire study product at any test visit. Data are reported as means \pm standard error of 
the mean (SEM) or median with interquartile limits for the MITT sample. Differences between the MITT and PP samples are noted if present.

The co-primary outcome variables were the changes from baseline to the end of treatment for the GI tolerability questionnaire composite score and the SGI questionnaire overall composite score, both of which reflected chronic dosing effects. Secondary outcome variables included differences between baseline and the end of treatment for individual scores of the GI tolerability questionnaire (nausea, gas/bloating, flatulence, cramping, and diarrhea/loose stools), the SGI questionnaire (memory, attention, speed of thinking) and the computerized cognitive function tasks (two tasks for each domain; attention/concentration, memory, planning, reasoning; Table 1). Cognitive function scores were evaluated for acute ( -1 to 2.25 and $4 \mathrm{~h}$ at baseline) and chronic (baseline to end of treatment using the $-1 \mathrm{~h}$ assessment) differences. Exploratory outcome variables were evaluated both acutely at the baseline test visit (day 0; differences between -1.25 and both 0.5 and $2 \mathrm{~h}$ assessments) and chronically (differences between baseline and end of treatment using the $-1.25 \mathrm{~h}$ assessment) in free and conjugated plasma rosmarinic acid metabolites.

\section{RESULTS}

\section{Subjects}

In total, 20 participants were screened for this trial and 11 eligible subjects were identified. Of the 11 subjects who were enrolled in the study, one subject withdrew consent after the baseline test visit due to their inability to understand the cognitive function tests; this subject was also removed from the PP sample. A second subject was removed from the PP sample due to $134 \%$ compliance for study product consumption. Therefore, the MITT sample included 11 subjects at baseline and 10 completers, whereas the PP sample included 9 individuals at each assessment. A single adverse event, back pain, was reported during the treatment period and coded as unrelated to the study product consumption.

Baseline characteristics of the MITT sample $(\mathrm{N}=11)$ are included in Table 2.

Table 2. Baseline characteristics of subjects in the modified intention-to-treat sample

\begin{tabular}{lc}
\hline Parameter & Overall Value $(\mathbf{N}=\mathbf{1 1})$ \\
\hline & $\mathrm{n}(\%)$ \\
Male & $3(27)$ \\
Female & $8(73)$ \\
Race/Ethnicity & \\
$\quad$ Non-Hispanic White & $10(91)$ \\
Black/African American & $1(9)$ \\
\cline { 2 - 2 } Age (years) & Mean (SEM) \\
Body mass index $\left(\mathrm{kg} / \mathrm{m}^{2}\right)$ & $58.7(1.6)$ \\
MAC-Q score & $27.4(1.0)$ \\
MMSE score & $29.7(1.0)$ \\
\hline
\end{tabular}

Abbreviations: MAC-Q, Memory Assessment Clinic Scale Questionnaire; MMSE, Mini-Mental State Exam 
The sample comprised of $27 \%$ males and $73 \%$ females, with mean age and BMI of $58.7 \pm 1.6 \mathrm{y}$ and $27.4 \pm 1.0 \mathrm{~kg} / \mathrm{m}^{2}$, respectively. Mean overall compliance with study product consumption was $103.2 \pm 3.3 \%$. Mean scores for the qualifying MAC-Q and MMSE were $29.7 \pm 1.0$ and 28.9 \pm 0.4 , respectively.

\section{Tolerability}

Consumption of the spearmint extract did not significantly alter individual GI symptoms (constipation, cramping, flatulence, gas/bloating, loose stools, and nausea) between baseline and the end of treatment ( $\mathrm{P}=1.000$ for all comparisons; data not shown). Furthermore, the GI tolerability composite score did not change significantly between baseline and the end of treatment $(\mathrm{P}=1.000$; data not shown).

Mean and median values for vital signs and fasting lipoprotein lipids, at both baseline and end of treatment and the change from baseline, are presented in Table 3.

Table 3. Vital signs and fasting lipoprotein lipids at baseline, end of treatment, and change from baseline in response to spearmint supplementation

\begin{tabular}{|c|c|c|c|c|}
\hline Parameter & Baseline $^{1}$ & EOT $^{2}$ & Difference $(\Delta)$ & P-value ${ }^{3}$ \\
\hline & \multicolumn{3}{|c|}{ Mean (SEM) or Median (Interquartile Limits) } & \\
\hline $\mathrm{SBP}(\mathrm{mm} \mathrm{Hg})$ & $121.1(3.6)$ & $121.7(3.3)$ & $-0.9(2.4)$ & 0.706 \\
\hline $\mathrm{DBP}(\mathrm{mm} \mathrm{Hg})$ & $75.3(2.5)$ & $78.3(2.6)$ & $1.3(2.3)$ & 0.603 \\
\hline Heart rate (bpm) & $63.2(2.2)$ & $68.0(2.7)$ & $3.7(1.8)$ & 0.077 \\
\hline Body weight $(\mathrm{kg})$ & $77.1(2.6)$ & $77.8(2.9)$ & $0.4(0.3)$ & 0.212 \\
\hline LDL-C (mg/dL) & $138.6(11.5)$ & $148.6(11.4)$ & $5.2(5.4)$ & 0.361 \\
\hline Non-HDL-C (mg/dL) & $156.6(10.8)$ & $163.7(11.6)$ & $3.1(5.5)$ & 0.584 \\
\hline $\mathrm{TC}(\mathrm{mg} / \mathrm{dL})$ & $213.1(11.5)$ & $222.3(12.5)$ & $3.4(6.0)$ & 0.586 \\
\hline HDL-C (mg/dL) & $56.6(3.4)$ & $58.6(3.2)$ & $0.3(1.6)$ & 0.858 \\
\hline Triglycerides (mg/dL) & $88.2(8.8)$ & $75.7(6.1)$ & $-9.3(8.3)$ & 0.293 \\
\hline TC/HDL-C & $3.7(3.1,4.3)$ & $3.6(3.4,4.5)$ & $0.1(-0.1,0.3)$ & 0.432 \\
\hline
\end{tabular}

Abbreviations: bpm, beats per minute; DBP, diastolic blood pressure; HDL-C, high-density lipoprotein cholesterol; LDL-C, low-density lipoprotein cholesterol; SBP, systolic blood pressure; TC, total cholesterol.

${ }^{1}$ Baseline refers to pre-dose values on day $0(\mathrm{~N}=11)$.

${ }^{2}$ End of treatment (EOT) refers to pre-dose values on day $30(n=10)$.

${ }^{3} \mathrm{P}$-values were calculated from paired t-tests or Wilcoxon sign rank test, between baseline and end of treatment in the modified intention-to-treat sample.

No significant differences in lipid parameters were evident over the 30-day treatment period in the MITT sample. An increase in LDL cholesterol in the PP sample was evident over the treatment period $(137.0 \pm 10.7$ vs. $145.89 \pm 12.4 \mathrm{mg} / \mathrm{dL} ; \mathrm{P}=0.079)$. Heart rate increased slightly over the 30 -day treatment period $(63.2 \pm 2.2$ vs. $68.0 \pm 2.6 \mathrm{bpm} ; \mathrm{P}=0.077)$ in the MITT population; however, this change was no longer significant in the PP sample $(\mathrm{P}=0.155)$. Body weight increased over the 30-day treatment period in the PP sample $(77.0 \pm 3.2 \mathrm{vs} .77 .6 \pm 3.3 \mathrm{~kg}$; 
$\mathrm{P}=0.062$ ), but not in the MITT sample. Blood chemistry and hematology values at baseline and end of treatment, and the change from baseline are presented in Tables 4 and 5.

Table 4. Plasma chemistry panel values at baseline, end of treatment, and change from baseline, in response to spearmint supplementation

\begin{tabular}{lcccc}
\hline \multicolumn{1}{c}{ Parameter } & Baseline $^{\mathbf{1}}$ & EOT $^{2}$ & Difference $(\boldsymbol{\Delta})^{\text {P-value }^{\mathbf{3}}}$ \\
\cline { 2 - 4 } Glucose (mg/dL) & $94.9(1.5)$ & $97.3(2.1)$ & $1.6(1.5)$ & 0.318 \\
Sodium (mmol/L) & $140.3(0.4)$ & $140.2(0.3)$ & $-0.1(0.5)$ & 0.847 \\
Potassium (mmol/L) & $4.4(0.1)$ & $4.6(0.1)$ & $0.1(0.2)$ & 0.447 \\
Chloride (mmol/L) & $104.9(0.6)$ & $105.5(0.8)$ & $0.2(0.9)$ & 0.836 \\
Carbon dioxide & $29.5(0.4)$ & $29.8(0.6)$ & $0.6(0.4)$ & 0.193 \\
(mmol/L) & $13.6(0.8)$ & $14.1(1.0)$ & $0.4(0.8)$ & 0.637 \\
BUN (mg/dL) & $0.9(0.0)$ & $0.9(0.1)$ & $0.0(0.0)$ & 0.515 \\
Creatinine (mg/dL) & $15.7(1.2)$ & $16.4(1.8)$ & $0.5(1.6)$ & 0.785 \\
BUN/Creatinine & $5.9(0.5)$ & $4.9(0.4)$ & $-0.9(0.4)$ & $\mathbf{0 . 0 6 8}$ \\
Anion gap (mmol/L) & $9.6(0.1)$ & $9.4(0.1)$ & $-0.2(0.0)$ & $\mathbf{0 . 0 0 7}$ \\
Calcium (mg/dL) & $290.6(0.8)$ & $290.7(0.8)$ & $-0.1(1.1)$ & 0.931 \\
Calcium osmolality & $22.2(1.5)$ & $22.6(1.8)$ & $0.4(1.4)$ & 0.786 \\
(mOs/kg) & $20.3(1.7)$ & $19.8(2.0)$ & $-0.6(2.1)$ & 0.776 \\
AST (U/L) & $69.9(5.7)$ & $66.7(5.6)$ & $-1.5(1.0)$ & 0.169 \\
ALT (U/L) & $0.8(0.1)$ & $0.7(0.1)$ & $-0.0(0.1)$ & 0.790 \\
ALP (U/L) & $6.9(0.2)$ & $6.7(0.2)$ & $-0.2(0.1)$ & $\mathbf{0 . 0 5 5}$ \\
Total bilirubin (mg/dL) & $4.0(0.1)$ & $3.9(0.1)$ & $-0.1(0.1)$ & 0.111 \\
Total protein (g/dL) & $2.9(0.2)$ & $2.9(0.2)$ & $-0.1(0.1)$ & 0.421 \\
Albumin (g/dL) & & & \\
Globulin (g/dL) & & & \\
\hline
\end{tabular}

Abbreviations: ALP, alkaline phosphatase; ALT, alanine transaminase; AST, aspartate aminotransferase; BUN, blood urea nitrogen; EOT, end of treatment.

${ }^{1}$ Baseline refers to pre-dose values on day $0(\mathrm{~N}=11)$.

${ }^{2}$ End of treatment $($ EOT) refers to pre-dose values on day $30(n=10)$.

${ }^{3} \mathrm{P}$-values were calculated from paired t-tests or Wilcoxon sign rank test, between baseline and end of treatment in the modified intention-to-treat sample.

Values from the blood chemistry panel in the MITT sample revealed declines in calcium (9.6 \pm 0.1 vs. $9.4 \pm 0.1 \mathrm{mg} / \mathrm{dL}, \mathrm{P}=0.007)$, anion gap ( $5.9 \pm 0.5$ vs. $4.9 \pm 0.4 \mathrm{mmol} / \mathrm{L}, \mathrm{P}=0.068)$, and total protein $(6.9 \pm 0.2$ vs. $6.7 \pm 0.2 \mathrm{mg} / \mathrm{dL}, \mathrm{P}=0.055)$ between baseline and end of treatment, respectively. These differences were also evident in the PP sample. However, the noted differences in heart rate, LDL cholesterol, body weight, and blood chemistry values are within normal ranges and biological variability, and are therefore not considered clinically 
relevant. Moreover, no significant differences were evident over the 30-day treatment for whole blood hematology values.

Table 5. Whole-blood hematology panel values at baseline, end of treatment, and change from baseline, in response to spearmint supplementation

\begin{tabular}{|c|c|c|c|c|}
\hline Parameter & Baseline $^{1}$ & EOT $^{2}$ & Difference $(\Delta)$ & P-value ${ }^{3}$ \\
\hline & \multicolumn{3}{|c|}{ Mean (SEM) or Median (Interquartile limits) } & \\
\hline $\mathrm{WBC}($ cells $/ \mu \mathrm{L})$ & $5.6(4.1,6.9)$ & $4.6(4.2,6.3)$ & $0.3(-0.1,0.4)$ & 0.447 \\
\hline $\mathrm{RBC}\left(\right.$ cells $\left.\times 10^{6} / \mu \mathrm{L}\right)$ & $4.5(0.1)$ & $4.6(0.1)$ & $0.1(0.1)$ & 0.529 \\
\hline Hemoglobin $(\mathrm{g} / \mathrm{dL})$ & $13.4(0.2)$ & $13.6(0.3)$ & $0.2(0.3)$ & 0.529 \\
\hline Hematocrit (\%) & $39.9(0.7)$ & $40.4(0.9)$ & $0.4(0.9)$ & 0.634 \\
\hline MCV (fL) & $88.4(1.6)$ & $88.5(1.7)$ & $-0.0(0.4)$ & 0.980 \\
\hline MCH (pg/cell) & $29.7(0.7)$ & $29.8(0.7)$ & $0.1(0.2)$ & 0.648 \\
\hline Platelets (cells x $\left.10^{3} / \mu \mathrm{L}\right)$ & $221.7(8.6)$ & $222.5(11.2)$ & $0.3(2.5)$ & 0.906 \\
\hline Neutrophils (cells $\times 10^{3} / \mu \mathrm{L}$ ) & $3.1(0.3)$ & $3.0(0.3)$ & $-0.0(0.2)$ & 0.916 \\
\hline Lymphocytes (cells x $10^{3} / \mu \mathrm{L}$ ) & $1.7(0.1)$ & $1.7(0.2)$ & $0.0(0.1)$ & 0.713 \\
\hline Monocytes (cells x $10^{3} / \mu \mathrm{L}$ ) & $0.5(0.0)$ & $0.5(0.1)$ & $0.0(0.0)$ & 0.193 \\
\hline Eosinophils (cells x $10^{3} / \mu \mathrm{L}$ ) & $0.1(0.1,0.2)$ & $0.1(0.1,0.2)$ & $0.0(0.0,0.0)$ & 0.500 \\
\hline Basophils (cells $\times 10^{3} / \mu \mathrm{L}$ ) & $0.1(0.0,0.1)$ & $0.1(0.0,0.1)$ & $0.0(0.0,0.0)$ & 1.000 \\
\hline
\end{tabular}

Abbreviations: EOT, end of treatment; $\mathrm{MCH}$, mean corpuscular hemoglobin; $\mathrm{MCV}$, mean corpuscular volume; $\mathrm{RBC}$, red blood cells; WBC, white blood cells.

${ }^{1}$ Baseline refers to pre-dose values on day $0(\mathrm{~N}=11)$.

${ }^{2}$ End of treatment (EOT) refers to pre-dose values on day $30(\mathrm{n}=10)$.

${ }^{3} \mathrm{P}$-values were calculated from paired t-tests or Wilcoxon sign rank test, between baseline and end of treatment in the modified intention-to-treat sample.

\section{Plasma Rosmarinic Acid Metabolites}

Mean concentrations of plasma rosmarinic acid metabolites following acute administration of spearmint during the baseline test visit are shown in Figure 1. Among the SRM transition analyses, a number of metabolites were detected following acute administration, including vanillic acid sulfate, caffeic acid sulfate, dihydrocaffeic acid sulfate, ferulic acid sulfate, dihydroferulic acid sulfate and rosmarinic acid. A compound with a $\mathrm{m} / \mathrm{z}$ equal to 549 , which fragmented and produced an ion with a $\mathrm{m} / \mathrm{z}$ of 373 , was most likely methyl rosmarinic acid glucuronide, although the standard compound was not available. Vanillic acid sulfate, caffeic acid sulfate and ferulic acid sulfate were significantly elevated in plasma at $0.5 \mathrm{~h}$ by 124,168 , $150 \%$, and at $2 \mathrm{~h}$ by $181,219,260 \%$, respectively, relative to the pre-dose assessment at baseline ( $\mathrm{P}<0.02$ for all comparisons). At baseline, rosmarinic acid was undetectable in plasma drawn at the pre-dose assessment, but was significantly elevated in plasma $2 \mathrm{~h}$ after supplement consumption $(11.5 \pm 4.89 \mathrm{nM}, \mathrm{P}=0.016)$. Mean plasma methyl rosmarinic acid glucuronide 
was also significantly elevated at $0.5 \mathrm{~h}$ following supplement consumption, relative to the predose assessment $(30.2 \pm 4.4$ vs. $23.3 \pm 4.9 \mathrm{nM}, \mathrm{P}=0.034)$. However, this difference was no longer significant at the $2 \mathrm{~h}$ assessment $(\mathrm{P}=0.289)$. Due to the relatively high concentrations of dihydrocaffeic acid sulfate and dihydroferulic acid sulfate at the pre-dose assessment, which may be related to the consumption of their precursors in coffee and wheat-based products, no differences were detected at 0.5 or $2 \mathrm{~h}$ after supplementation at baseline $(\mathrm{P}>0.1)[37,38]$.

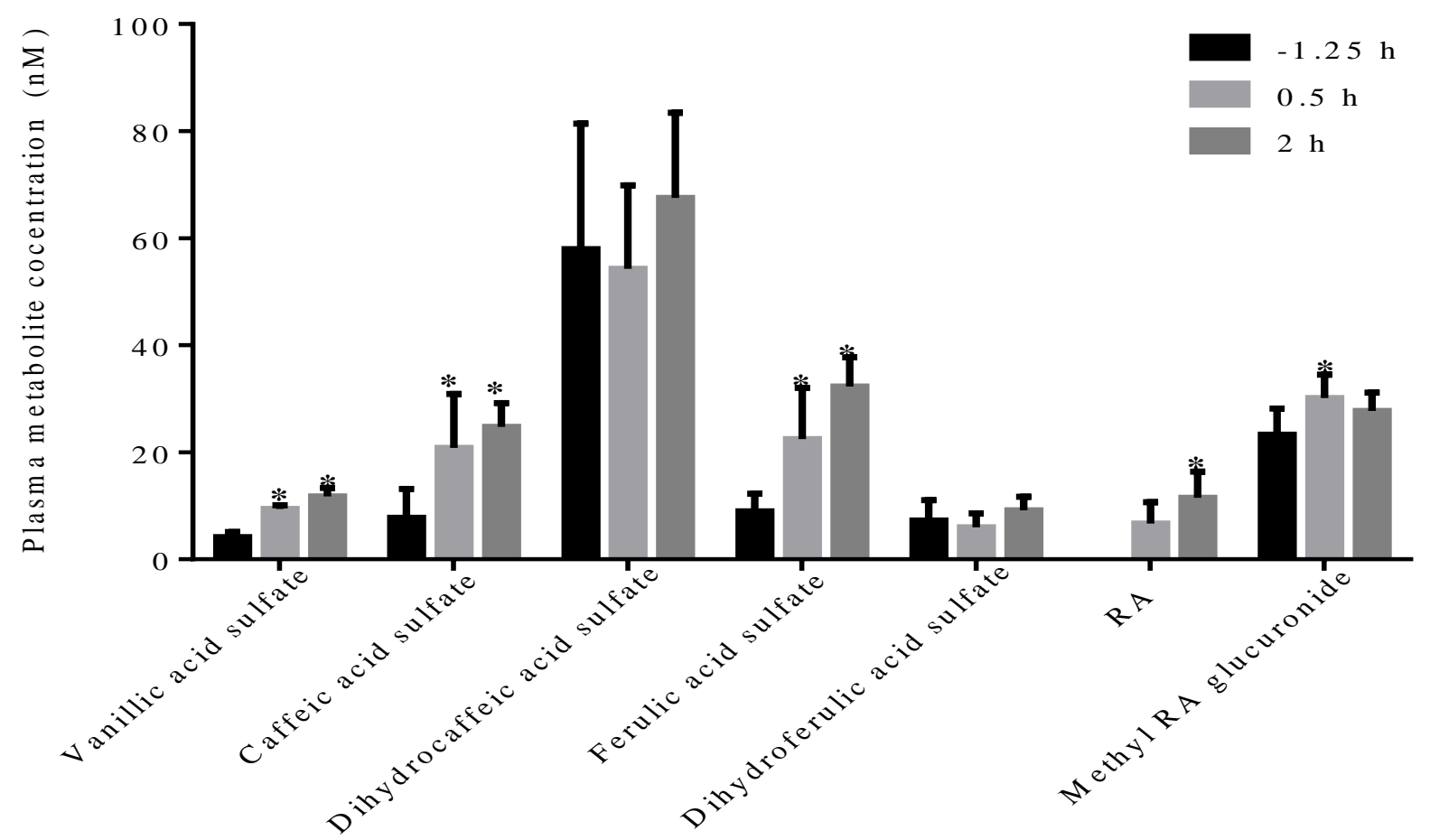

Figure 1. Acute assessment of plasma rosmarinic acid metabolites following spearmint supplementation. Subjects $(n=10)$ consumed $900 \mathrm{mg} /$ day spearmint extract and blood was drawn pre-dose $(-1.25 \mathrm{~h})$ and post-dose $(0.5$ and $2 \mathrm{~h})$. Vanillic acid sulfate, caffeic acid sulfate, ferulic acid sulfate and dihydroferulic acid sulfate were quantified as ferulic acid-4- $O$-sulfate equivalents; dihydrocaffeic acid sulfate was expressed as as dihydrocaffeic acid 3-O-sulfate equivalents. Rosmarinic acid (RA) and methyl RA glucuronide were quantified as RA equivalents. Bars represent mean scores \pm SEM. P-values were calculated between pre-dose $(-1.25 \mathrm{~h})$ and post-dose $(0.5$ and 2 h) assessments using a paired t-test or the Wilcoxon signed-rank test. *Significant difference $(\mathrm{P}<0.05)$. Abbreviation: $\mathrm{RA}$, rosmarinic acid.

The chronic assessment of the plasma rosmarinic acid metabolites following 30 days of spearmint supplementation are presented in Figure 2. Methyl rosmarinic acid glucuronide was elevated in the plasma over the 30 day intervention, relative to the baseline assessment $(30.1 \pm$ 4.0 vs. $23.3 \pm 4.88 \mathrm{nM}, \mathrm{P}=0.082$ ). This difference was no longer significant in the PP sample $(\mathrm{P}=0.107)$. Nonetheless, further investigation is warranted due to the lack of an available standard and the unexpectedly high levels detected at baseline. Mean plasma vanillic acid sulfate was reduced over the 30 day supplementation period, relative to baseline $(2.6 \pm 0.6$ vs. $4.2 \pm 0.9 \mathrm{nM}, \mathrm{P}=0.037$ ). However, no significant differences were evident in any of the additional metabolites detected (caffeic acid sulfate, dihydrocaffeic acid sulfate, ferulic acid sulfate, and rosmarinic acid) following chronic supplementation. 


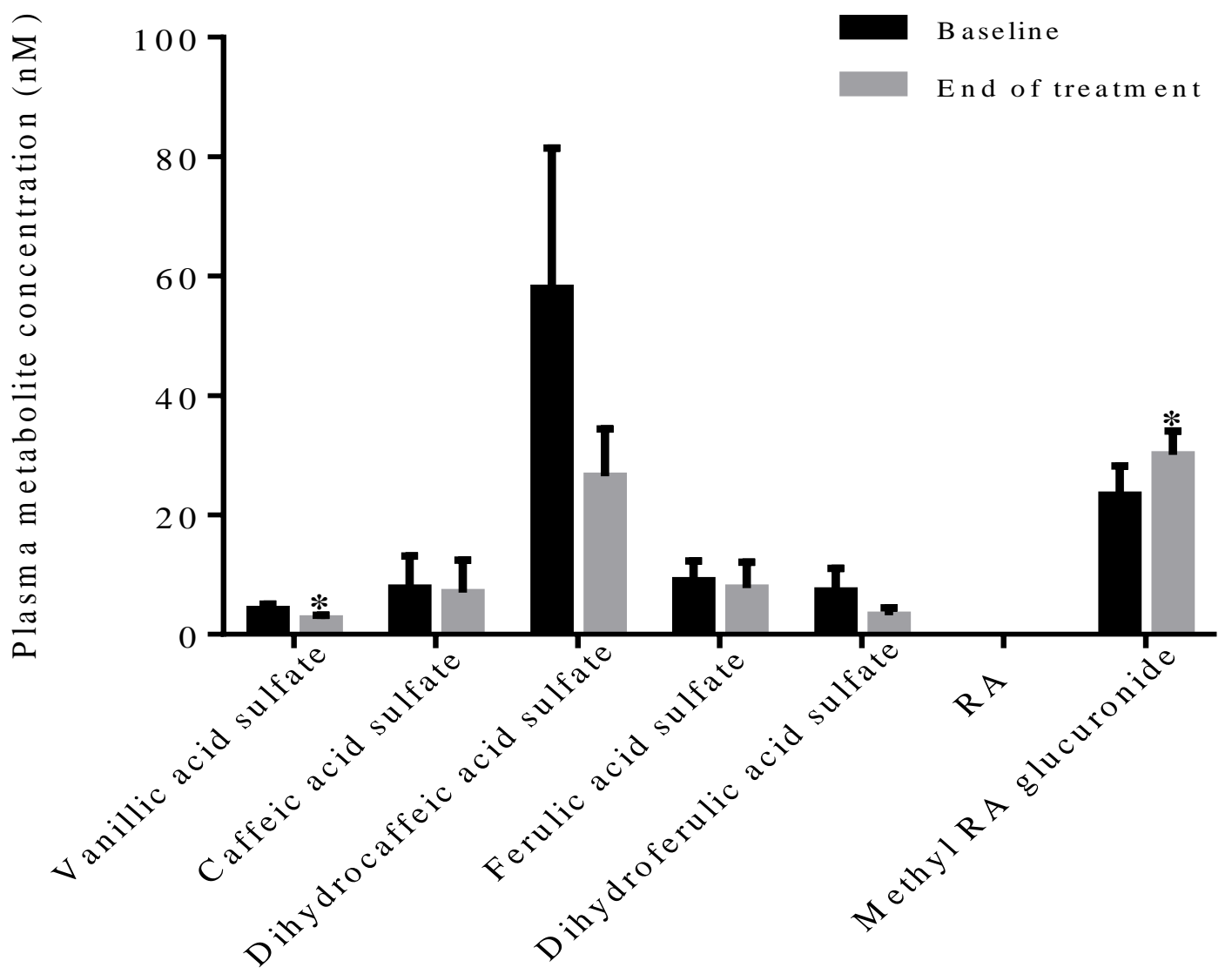

Figure 2. Chronic differences in plasma rosmarinic acid metabolites following 30 days of spearmint supplementation. Subjects $(\mathrm{n}=10)$ consumed $900 \mathrm{mg} /$ day spearmint extract and blood was drawn at baseline (day 0) and the end of treatment (day 30) at the pre-dose assessment $(\mathrm{t}=-1.25 \mathrm{~h})$. Vanillic acid sulfate, caffeic acid sulfate, ferulic acid sulfate and dihydroferulic acid sulfate were quantified as ferulic acid-4- $O$-sulfate equivalents; dihydrocaffeic acid sulfate was expressed as as dihydrocaffeic acid 3- $O$-sulfate equivalents. Rosmarinic acid (RA) and methyl RA glucuronide, were quantified as RA equivalents. Bars represent mean scores \pm SEM. P-values were calculated between pre-dose $(-1.25 \mathrm{~h})$ assessment at baseline and end of treatment using a paired t-test or the Wilcoxon signedrank test. *Significant difference $(\mathrm{P}<0.09)$. Abbreviation: RA, rosmarinic acid.

\section{Cognitive Function}

Mean scores from the acute assessment of cognitive function using the computerized brain training tasks administered during the baseline test visit are represented in Figure 3. Acute cognitive function evaluation at baseline suggests improvement in mean scores for attention/concentration 1 task from pre-dose to 2.25 and $4 \mathrm{~h}$ post-dose by $30 \%(19.0 \pm 8.2$ points, $\mathrm{P}=0.042)$ and $46 \%(29.1 \pm 6.6$ points, $\mathrm{P}=0.001)$, relative to the pre-dose assessment, respectively. Similarly, mean scores from the attention/concentration 2 task increased between the pre-dose and 2.25 and $4 \mathrm{~h}$ post-dose assessments by $93 \%(16.8 \pm 6.4$ points, $\mathrm{P}=0.025)$ and $121 \%(21.8 \pm 5.3$ points, $\mathrm{P}=0.002)$, respectively. Mean scores from the planning 2 task were also significantly elevated by $39 \%(11.7 \pm 3.2$ points; $\mathrm{P}=0.004)$ at the $4 \mathrm{~h}$ post-dose, relative to the pre-dose assessment. 


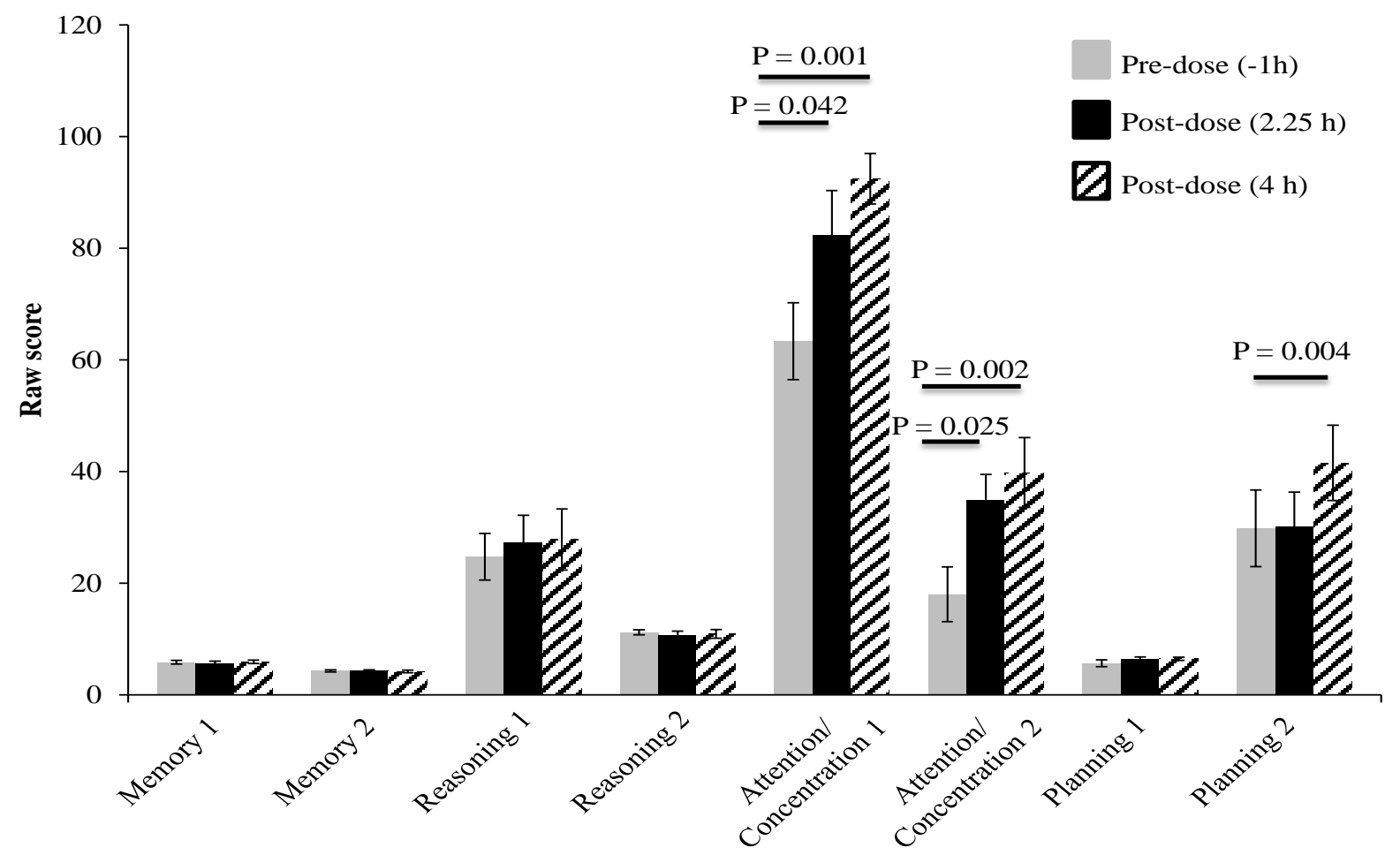

Figure 3. Cognitive function scores before and after acute spearmint supplementation. Subjects $(n=$ 10-11) consumed $900 \mathrm{mg} /$ day spearmint extract and completed a battery of publicly available cognitive function tasks (Cambridge Brain Sciences, London, Ontario, Canada; http://www.cambridgebrainsciences.com) to assess memory, reasoning, attention/concentration, and planning during the baseline test visit at the pre-dose assessment $(\mathrm{t}=-1 \mathrm{~h})$ and post-dose $(2.25 \mathrm{and} 4 \mathrm{~h})$. The battery included eight tasks: digit span (memory 1), paired associates (memory 2), double trouble (reasoning 1), odd one out (reasoning 2), rotations (attention/concentration 1), polygons (attention/concentration 2), spatial search (planning 1), and spatial slider (planning 2). Bars represent mean scores \pm SEM. P-values were calculated between pre-dose and post-dose assessments using a paired t-test or the Wilcoxon signed-rank test.

The chronic assessment of cognitive function using the computerized brain training task scores administered at the pre-dose timepoints $(-1 \mathrm{~h})$ during the baseline and end of treatment visits, are represented in Figure 4. Scores from reasoning 1, attention/concentration 2, and planning 2 cognitive function tasks improved between baseline and the end of treatment by $35 \%$ $(6.4 \pm 4.2$ points; $\mathrm{P}=0.023), 125 \%(22.9 \pm 5.3$ points; $\mathrm{P}=0.002)$, and $48 \%(11.3 \pm 5.9 ; \mathrm{P}=$ 0.088), relative to the pre-dose assessment $(\mathrm{t}=-1 \mathrm{~h})$. Scores from reasoning 1 and attention/concentration 2 remained significant $(\mathrm{P}=0.030$ and $\mathrm{P}=0.004$, respectively), although the change in the planning 2 task score was no longer significant $(P=0.169)$ in the PP sample. All other chronic assessment scores from the cognitive function tasks did not differ significantly between baseline and end of treatment.

Mean scores from the SGI Questionnaire, which assessed change from baseline in three domains of cognition (memory, attention, and speed of thinking), are shown in Table 6 . A modest improvement was demonstrated in the average composite score from the SGI Questionnaire (3.5 \pm 0.3 vs. a score of 4 representing 'no change'; $\mathrm{P}=0.063)$ after 30 days of supplementation. The difference in the average composite score (from a score of 4), was no longer significant in the $\mathrm{PP}$ sample $(\mathrm{P}=0.125)$. There were no significant differences in individual ratings from the SGI Questionnaire. 
Table 6. Subject Global Impression (SGI) scale of cognition questionnaire scores at the end of treatment in response to spearmint supplementation ${ }^{1}$

\begin{tabular}{lll}
\hline Parameter & Mean (SEM) & P-value $^{2}$ \\
\hline Memory & $3.7(0.2)$ & 0.500 \\
Attention & $3.5(0.2)$ & 0.125 \\
Speed of thinking & $3.4(0.3)$ & 0.125 \\
Average score & $3.5(0.2)$ & $\mathbf{0 . 0 6 3}$ \\
\hline
\end{tabular}

Abbreviations: SEM, standard error of the mean.

${ }^{1}$ The SGI questionnaire was administered at the end of the 30-day treatment and subjects were asked to compare their current condition to their condition prior to inclusion in the study. Scores were coded as: $1=$ very much improved, $2=$ much improved, $3=$ minimally improved, $4=$ no change, $5=$ minimally worse, $6=$ much worse, $7=$ very much worse.

${ }^{2} \mathrm{P}$-values were calculated from Wilcoxon sign rank test, testing the difference from 4 (no change; $\mathrm{n}=10$ ) at the end of treatment in the modified intention-to-treat sample.

\section{DISCUSSION}

A limited number of previously published studies have evaluated the tolerance of aqueous spearmint extracts in humans at dose levels which exceed what would typically be consumed as a seasoning or flavoring. For example, one study enrolled female subjects with hirsutism $(\mathrm{N}=$ 21 ; mean age $=22 \mathrm{y}$ ) to evaluate the antiandrogenic effects of spearmint tea [39]. Subjects consumed 500

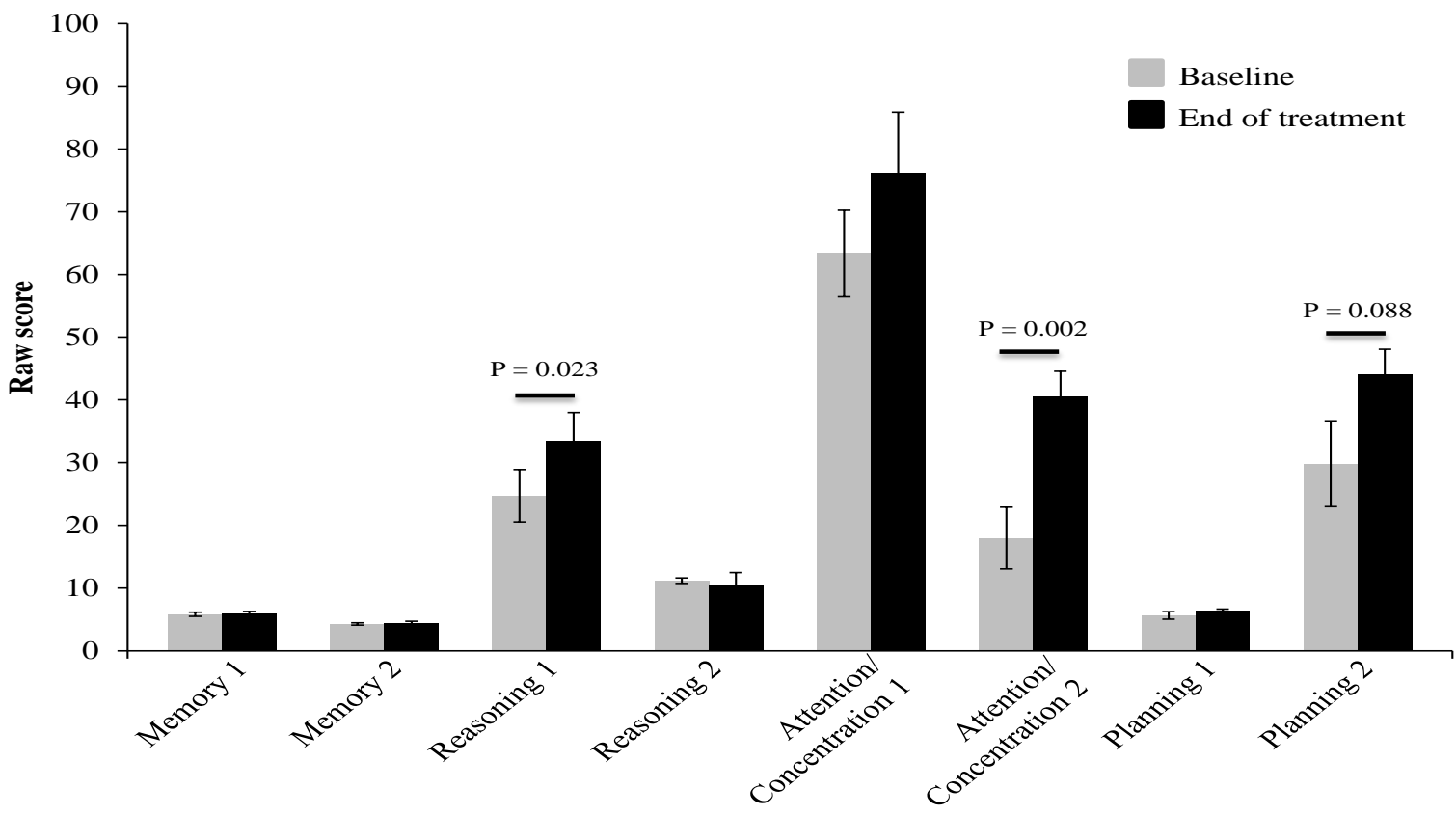

Figure 4. Chronic differences in cognitive function assessed at baseline and at the end of a 30day period of spearmint supplementation. Subjects $(n=10-11)$ consumed $900 \mathrm{mg} /$ day spearmint extract and completed a battery of publicly available cognitive function tasks (Cambridge Brain Sciences, London, Ontario, Canada; http://www.cambridgebrainsciences.com) to chronically assess memory, reasoning, attention/concentration, and planning at baseline (day 0 ) and the end of treatment (day 30) at the pre-dose assessment $(\mathrm{t}=-1 \mathrm{~h})$. The battery included eight tasks: digit span (memory 1 ), paired associates (memory 2), double trouble (reasoning 1), odd one out (reasoning 2), rotations (attention/concentration 1), polygons (attention/concentration 2), spatial search (planning 1), and spatial slider (planning 2). Bars represent mean scores \pm SEM. P-values were calculated between baseline and end of treatment using a paired t-test or the Wilcoxon signed-rank test. 
$\mathrm{mL}$ of tea/day for five days, prepared with $10 \mathrm{~g}$ spearmint [40]. Free testosterone was significantly reduced while luteinizing hormone and follicle stimulating hormone levels increased, relative to baseline $(\mathrm{P}<0.05)$, following consumption of the spearmint tea. Additionally, biochemical tolerance parameters were assessed including plasma glucose, hepatic enzymes, and lipids. A reduction in triglycerides was the only significant $(\mathrm{P}<0.05)$ finding over the brief supplementation period and was not confirmed after 30 days of supplementation in this study.

A few studies have also evaluated spearmint toxicity in animal models. Specifically, in a study by Akdogan et al. [41], rats ( $=12$ /group) were fed spearmint tea (20 and $40 \mathrm{~g} / \mathrm{L}) \mathrm{ad}$ libitum or the vehicle water for 30 days. Plasma concentrations of urea and creatinine were significantly elevated $(\mathrm{P}<0.003)$ at both dose levels, relative to the control, following spearmint tea consumption. Similarly, a second study using the same study design in rats also reported significant elevations at both dose levels in activity of hepatic enzymes, aspartate aminotransferase (AST) and alanine aminotransferase (ALT), relative to control $(\mathrm{P}<0.016)[42]$. Spearmint intake was estimated at $2.2 \mathrm{~g} / \mathrm{kg}$ body weight $(20 \mathrm{~g} / \mathrm{L})$ and $4.4 \mathrm{~g} / \mathrm{kg}$ body weight (40 $\mathrm{g} / \mathrm{L}$ ) per day in these studies, which roughly translates to a $25-50 \mathrm{~g} /$ day dose in a $70 \mathrm{~kg}$ human [18]. The estimated levels of spearmint consumption in these animal studies were $\sim 3$-fold higher per $\mathrm{kg}$ body weight than that consumed in the current study, and no elevations were observed among participants in urea, creatinine, or hepatic enzymes.

Little is known regarding the bioavailability of aqueous spearmint extracts in humans. In a study by Baba et al. [43], rosmarinic acid was orally administered to rats at $50 \mathrm{mg} / \mathrm{kg}$ body weight. Rosmarinic acid, methyl rosmarinic acid, and coumaric acid were detected in the plasma largely as sulfated and glucuronidated conjugates. After oral administration, peak concentrations were reported at $0.5,1$, and $8 \mathrm{~h}$ for rosmarinic acid, methyl rosmarinic acid, and coumaric acid, respectively. In a follow-up study, the aqueous Lamiaceae extract Perilla frutescens, containing $200 \mathrm{mg}$ rosmarinic acid (w/w), or placebo were administered to healthy male subjects (mean age = $37 \mathrm{y}$ ) in a crossover design [44]. Rosmarinic, methyl rosmarinic, and ferulic acids were detected in plasma. These metabolites were present mainly as conjugates (glucuronidated and sulfated) rather than in their free form, similar to the results reported here, with peak concentrations at $0.5,2$, and $0.5 \mathrm{~h}$ for rosmarinic, methyl rosmarinic, and ferulic acids, respectively, following consumption of the Perilla frutescens extract. In contrast, rosmarinic acid sulfate, rosmarinic acid glucuronide, methyl rosmarinic acid, ferulic acid and ferulic acid glucuronide were not detected in the plasma of subjects following supplement consumption in this study, while vanillic acid sulfate, caffeic acid sulfate, dihydrocaffeic acid sulfate and dihydroferulic acid sulfate were present. No significant differences were evident in dihydrocaffeic acid sulfate and dihydroferulic acid sulfate following acute spearmint consumption in this study, which could be partially explained by the contribution of the colonic microflora to the metabolism of other phenolic compounds from other sources in the diet, such as grains and coffee [37, 38]. Interindividual differences in colonic microflora may also account for the variation in plasma concentrations of these metabolites. It is also possible that rosmarinic acid, a hydroxycinnamic acid and caffeic acid ester, may be cleaved in the small intestine and further metabolized and/or conjugated prior to absorption, according to similar reports following consumption of other hydroxycinnamic acids (e.g. cholorgenic acids) [45, 46]. 
Conflicting evidence exists regarding the effects of spearmint on cognitive function and are limited to spearmint chewing gum specifically. Mint chewing gum is commonly formulated with oil extracts and contains small amounts of extract, typically $0.1-5 \%(\mathrm{w} / \mathrm{w})$, but the composition and quantity of spearmint extract used in these trials were not described [14, 15]. Furthermore, the interpretation of these results is difficult, due to the absence of dosing information; it is also uncertain whether the improvement in memory and attention/concentration is the result of spearmint or the act of chewing, as a number of studies suggest the act of chewing alone may support cognitive function [47]. In this current study, acute supplementation with the spearmint extract was associated with improvements in attention/concentration tasks, but did not lead to improvements in memory.

It should be noted that several other studies have been conducted which investigated the effects of acute consumption of other extracts of plants within the Lamiaceae family on cognitive function. However, a majority of these studies evaluated the effects of either extracts of the essential oil fractions or the dried leaves of the plant. For example, randomized crossover trials indicate Spanish sage (Salvia lavandulaefolia) oil acutely improves memory up to $6 \mathrm{~h}$ after supplementation in healthy young (age $=18-37 \mathrm{y}$ ) participants, but no differences were evident in attention/concentration, compared to control [48, 49]. A follow-up study using a different cognitive function test battery in young adults (mean age $=23.8 \mathrm{y}$ ) demonstrates improvements in both memory and attention/concentration up to $4 \mathrm{~h}$ post-supplementation following an acute dose of Spanish sage oil, relative to control. In older subjects (mean age $=73.0 \mathrm{y} ; \mathrm{n}=24$ ), both memory and attention/concentration were improved up to $6 \mathrm{~h}$ post-supplementation following an acute $333 \mathrm{mg}$ dose of ethanol-extracted sage (Salvia officinalis) extract, relative to placebo [12]. Lemon balm (Melissa officinalis) improved memory at 1, 3, and $6 \mathrm{~h}$ following consumption of $1600 \mathrm{mg}$ of dried leaf extract in healthy young adults (mean age $=19 \mathrm{y}$ )[50]. Similarly, dried rosemary (Rosmarinus officinalis) extract improved memory within $6 \mathrm{~h}$ of an acute $750 \mathrm{mg}$ dose $(\mathrm{P}=.01)$ in elderly subjects (mean age $=75 \mathrm{y})$, but no differences were reported in attention/concentration, relative to placebo [13].

The various compounds in plants within the Lamiaceae family are likely responsible for the wide range of reported biological activity of these plant extracts [51]. Rosmarinic acid is one of the phenolic compounds in plants within the Lamiaceae family that may contribute to the reported activities of these extracts, including antioxidant and anticholinesterase activities [52]. The spearmint extract used in this trial contained 15\% rosmarinic acid, which significantly exceeds the typical $0-6 \%$ present in most extracts of Lamiaceae species and extracts from traditional spearmint lines grown for flavoring applications [30, 53, 54]. The antioxidant capacity of rosmarinic acid and/or its derived metabolites may also contribute to the observed effects of this spearmint extract on cognitive function. Acetylcholinesterase inhibitors (e.g., donepezil) and antioxidants (e.g., vitamin E) have been investigated in clinical trials for mild cognitive impairment and more advanced stages of cognitive dysfunction, including Alzheimer's disease [55, 56]. Rosmarinic acid fractions of lemon balm extracts have been shown to significantly inhibit acetylcholinesterase in a time- and dose-dependent manner [57]. Treatment with rosmarinic acid at $10 \mathrm{mg} / \mathrm{kg}$ body weight for 21 days significantly reduced acetylcholinesterase activity in the hippocampus, cortex, and striatum of diabetic rats, relative to placebo-treated diabetic animals [58]. In addition to rosmarinic acid, other phenolic compounds 
detected in the spearmint extract (Mena, Del Rio, et al. manuscript in preparation) have been reported to have antioxidant activity and could be contributing to the observed cognitive benefits as well [59, 60]. Furthermore, results of a recent systematic review of observational studies show the potential for protective effects of antioxidant nutrients against age-related cognitive decline; further investigation is clearly warranted [61].

While the current study exhibits strengths, there are also limiting factors, primarily due to the lack of a placebo control and blinding of participants to the treatment. This could have contributed to bias particularly in the self-reported outcomes. Additional limitations of the present work include that participants were free-living, consequently confounding by other dietary and/or lifestyle factors was possible. Although participants were asked to keep the number of hours they slept constant, the quality of sleep was not evaluated and may have contributed to cognitive performance $[62,63]$. Training effects and intentional poor performance can also limit studies designed for cognitive function testing [64, 65]. Nonetheless, participants did complete practice tests to reduce variability in the cognitive function test scores, with all tests completed under supervision; parallel versions of the tests were also available to control for this limitation. However, without the inclusion of a control group it is difficult to rule out the effects of practice. Finally, the current trial investigated the tolerance of the spearmint extract in a small sample which included only 50-70 y old subjects with subjective memory impairment. As a result of these limiting and varying factors, further examination is warranted.

\section{CONCLUSIONS}

This open-label, pilot trial demonstrated that consumption of the aqueous spearmint extract at $900 \mathrm{mg} /$ day for 30 days was well-tolerated and bioavailable. Although differences were evident in LDL cholesterol, anion gap, calcium, total protein, heart rate, and body weight, the observed differences were within normal biological variability, and therefore not considered clinically relevant. Plasma vanillic, caffeic, and ferulic acid sulfates, rosmarinic acid, and methyl rosmarinic acid glucuronide were detected in plasma within $2 \mathrm{~h}$ of aqueous spearmint extract administration. Moreover, methyl rosmarinic acid glucuronide was significantly elevated in plasma after 30 days of supplementation. The results of this trial suggest that chronic supplementation with the aqueous spearmint extract may impact cognitive function domains, including reasoning, attention/concentration, and planning, while acute intake may have positive effects on attention/concentration and planning, relative to baseline.

In conclusion, the aqueous spearmint extract, containing higher rosmarinic acid content relative to extracts from typical commercial lines, was well-tolerated and bioavailable in older subjects (50-70 y) with self-reported memory impairment. Additionally, the aqueous spearmint extract may have implications in cognitive health and warrants further investigation. Furthermore, the results of this trial are essential in guiding the design of follow-up randomized controlled trials to evaluate the effects of the aqueous spearmint extract on cognitive function.

Abbreviations: AST, aspartate aminotransferase; ALT, alanine aminotransferase; bpm, beats per minute; BUN, blood urea nitrogen; DBP, diastolic blood pressure; EOT, end of treatment; GI, gastrointestinal; HDL-C, high-density lipoprotein cholesterol; MAC-Q, Memory Assessment Clinic Scale Questionnaire; $\mathrm{MCH}$, mean corpuscular hemoglobin; $\mathrm{MCV}$, mean corpuscular volume; 
MMSE, Mini Mental State Examination; MITT, modified intention-to-treat; PP, per protocol; RA, rosmarinic acid; RBC, red blood cells; SBP, systolic blood pressure; SGI, Subject Global Impression; TC, total cholesterol; TG, triglycerides WBC, white blood cells.

Competing interests: Kemin Foods, L.C. funded this study. The authors acknowledge that they have either received research funding from, or are employees of Kemin Foods, L.C., the manufacturer of the ingredient studied.

Authors' contributions: K.M.N., K.D.S., M.A.C., K.C.M., and K.A.H conceived and designed the study. K.D.S., K.M.K., and A.L.L obtained ethics approval. K.D.S., L.B., D.D., A.L.L., and K.M.K. collected the data. A.L.S analyzed the data. K.M.N., M.A.C., K.M.K., A.L.L., K.C.M., L.B., D.D., A.L.S, and K.A.H. interpreted the data. K.M.N., L.B., D.D., and K.A.H. wrote the manuscript. All authors critically reviewed and revised the manuscript.

Acknowledgements: The authors would like to thank Barbara Anderson, MS, RD, for her contribution to protocol development, Eleanor Espinosa, BS, for her dedication to the coordination of this trial, the entire clinic staff at Biofortis Clinical Research for their commitment to this study, and Brenda Fonseca, MA and Joanne A. Lasrado, PhD, for their critical review of the manuscript.

\section{REFERENCES}

1. Jonker C, Geerlings MI, Schmand B. Are memory complaints predictive for dementia? A review of clinical and population-based studies. Int J Geriatr Psychiatry 2000, 15:983-91.

2. Jungwirth S, Fischer P, Weissgram S, Kirchmeyr W, Bauer P, Tragl KH. Subjective memory complaints and objective memory impairment in the Vienna-Transdanube aging community. J Am Geriatr Soc 2004, 52:263-8.

3. Gallo V, Leonardi G, Brayne C, Armstrong B, Fletcher T. Serum perfluoroalkyl acids concentrations and memory impairment in a large cross-sectional study. BMJ Open 2013, 3.

4. Waldorff FB, Rishoj S, Waldemar G. If you don't ask (about memory), they probably won't tell. J Fam Pract 2008, 57:41-4.

5. Grossi D, Postiglione A, Schettini B, Trojano L, Barbarulo AM, Giugliano V, et al. Autobiographical recall training in elderly adults with subjective memory complaint: a pilot study. Percept Mot Skills 2007, 104:621-8.

6. Plassman BL, Langa KM, Fisher GG, Heeringa SG, Weir DR, Ofstedal MB, et al. Prevalence of cognitive impairment without dementia in the United States. Ann Intern Med 2008, 148:427-34.

7. Wesnes KA, Ward T, McGinty A, Petrini O. The memory enhancing effects of a Ginkgo biloba/Panax ginseng combination in healthy middle-aged volunteers. Psychopharmacology 2000, 152:353-61. 
8. Snitz BE, O'Meara ES, Carlson MC, Arnold AM, Ives DG, Rapp SR, et al. Ginkgo biloba for preventing cognitive decline in older adults: a randomized trial. JAMA 2009, 302:2663-70.

9. Reay JL, Kennedy DO, Scholey AB. Single doses of Panax ginseng (G115) reduce blood glucose levels and improve cognitive performance during sustained mental activity. J Psychopharmacol 2005, 19:357-65.

10. Kennedy DO, Haskell CF, Wesnes KA, Scholey AB. Improved cognitive performance in human volunteers following administration of guarana (Paullinia cupana) extract: comparison and interaction with Panax ginseng. Pharmacol Biochem Behav 2004, 79:401-11.

11. Kennedy DO, Scholey AB, Tildesley NT, Perry EK, Wesnes KA. Modulation of mood and cognitive performance following acute administration of Melissa officinalis (lemon balm). Pharmacol Biochem Behav 2002, 72:953-64.

12. Scholey AB, Tildesley NT, Ballard CG, Wesnes KA, Tasker A, Perry EK, et al. An extract of Salvia (sage) with anticholinesterase properties improves memory and attention in healthy older volunteers. Psychopharmacology 2008, 198:127-39.

13. Pengelly A, Snow J, Mills SY, Scholey A, Wesnes K, Butler LR. Short-term study on the effects of rosemary on cognitive function in an elderly population. J Med Food 2012, 15:10-7.

14. Wilkinson L, Scholey A, Wesnes K. Chewing gum selectively improves aspects of memory in healthy volunteers. Appetite 2002, 38:235-6.

15. Tucha O, Mecklinger L, Maier K, Hammerl M, Lange KW. Chewing gum differentially affects aspects of attention in healthy subjects. Appetite 2004, 42:327-9.

16. Johnson AJ, Miles C. Chewing gum and context-dependent memory: the independent roles of chewing gum and mint flavour. Br J Psychol 2008, 99:293-306.

17. Farr SA, Niehoff ML, Ceddia MA, Herrlinger KA, Lewis BJ, Feng S, et al., editors. Antixoxidant extracts from rosemary and spearmint improve learning, memory and reduce oxidative stress in samp8 mice [Abstract \#436.14/T12]. Neuroscience, San Diego, CA; 2013.

18. Reagan-Shaw S, Nihal M, Ahmad N. Dose translation from animal to human studies revisited. FASEB J 2008, 22:659-61.

19. Nair B. Final report on the safety assessment of Mentha Piperita (Peppermint) Oil, Mentha Piperita (Peppermint) Leaf Extract, Mentha Piperita (Peppermint) Leaf, and Mentha Piperita (Peppermint) Leaf Water. Int J Toxicol 2001, 20 Suppl 3:61-73.

20. OECD OfECaD. Organisation for Economic Cooperation and Development. OECD Guidelines for the Testing of Chemicals, Section 4: Health Effects. Paris, France, 2009.

21. U.S. Food and Drug Administration. Redbook 2000: IV.B.1 General Guidelines for Designing and Conducting Toxicity Studies. Silver Spring, MD, 2003.

22. Lasrado JA, Trinker D, Ceddia MA, Herrlinger KA. The safety of a dry spearmint extract in vitro and in vivo. Regul Toxicol Pharmacol 2015, 71:213-24.

23. U.S. Food and Drug Administration. Substances generally recongized as safe: Essential oils, oleoresins (solvent-free), and natural extractives (including distillates). 12CRF182.20. Silver Spring, MD, 2014. 
24. U.S. Food and Drug Administration. Substances generally recongized as safe: Spices and other natural seasonsings and flavorings. 12CRF182.10. Silver Spring, MD, 2013.

25. World Medical Association Declaration of Helsinki: Ethical Principles for Medical Research Involving Human Subjects. JAMA 2013, 310:2191-4.

26. United States Deparment of Health and Human Services: 21CFR50: Protection of Human Subjects. Available at: http://www.accessdata.fda.gov/scripts/cdrh/cfdocs/cfcfr/CFRSearch.cfm.; 2013 [updated 2013; cited].

27. Crook TH, 3rd, Feher EP, Larrabee GJ. Assessment of memory complaint in ageassociated memory impairment: the MAC-Q. Int Psychogeriatr 1992, 4:165-76.

28. Dunbar GC, Kuchibhatla RV, Lee G. A randomized double-blind study comparing 25 and $50 \mathrm{mg}$ TC-1734 (AZD3480) with placebo, in older subjects with age-associated memory impairment. J Psychopharmacol 2011, 25:1020-9.

29. Folstein MF, Folstein SE, McHugh PR. "Mini-mental state". A practical method for grading the cognitive state of patients for the clinician. J Psychiatr Res 1975, 12:189-98.

30. Narasimhamoorthy B, Zhao LQ, Liu W, Yang W, Greaves JA. Differences in the chemotype of two native spearmint clonal lines selected for rosmarnic acid accumulation in comparison to commercially grown native spearmint. Ind Crops Prod 2015, 63:87-91.

31. Myers GL, Cooper GR, Winn CL, Smith SJ. The Centers for Disease Control-National Heart, Lung and Blood Institute Lipid Standardization Program. An approach to accurate and precise lipid measurements. Clin Lab Med 1989, 9:105-35.

32. Friedewald WT, Levy RI, Fredrickson DS. Estimation of the concentration of lowdensity lipoprotein cholesterol in plasma, without use of the preparative ultracentrifuge. Clin Chem 1972, 18:499-502.

33. Maki KC, Carson ML, Miller MP, Turowski M, Bell M, Wilder DM, et al. Hydroxypropylmethylcellulose and methylcellulose consumption reduce postprandial insulinemia in overweight and obese men and women. J Nutr 2008, 138:292-6.

34. Romo Vaquero M, Garcia Villalba R, Larrosa M, Yanez-Gascon MJ, Fromentin E, Flanagan $\mathrm{J}$, et al. Bioavailability of the major bioactive diterpenoids in a rosemary extract: metabolic profile in the intestine, liver, plasma, and brain of Zucker rats. Mol Nutr Food Res 2013, 57:1834-46.

35. Owen AM, Hampshire A, Grahn JA, Stenton R, Dajani S, Burns AS, et al. Putting brain training to the test. Nature 2010, 465:775-8.

36. Shapiro SS, Wilk MB. An analysis of variance test for normality (complete samples). Biometrika 1965, 52:591-611.

37. Calani L, Ounnas F, Salen P, Demeilliers C, Bresciani L, Scazzina F, et al. Bioavailability and metabolism of hydroxycinnamates in rats fed with durum wheat aleurone fractions. Food Funct 2014, 5:1738-46.

38. Del Rio D, Stalmach A, Calani L, Crozier A. Bioavailability of coffee chlorogenic acids and green tea flavan-3-ols. Nutrients 2010, 2:820-33.

39. Akdogan M, Ozguner M, Kocak A, Oncu M, Cicek E. Effects of peppermint teas on plasma testosterone, follicle-stimulating hormone, and luteinizing hormone levels and testicular tissue in rats. Urology 2004, 64:394-8. 
40. Akdogan M, Tamer MN, Cure E, Cure MC, Koroglu BK, Delibas N. Effect of spearmint (Mentha spicata Labiatae) teas on androgen levels in women with hirsutism. Phytother Res 2007, 21:444-7.

41. Akdogan M, Kilinc I, Oncu M, Karaoz E, Delibas N. Investigation of biochemical and histopathological effects of Mentha piperita L. and Mentha spicata L. on kidney tissue in rats. Hum Exp Toxicol 2003, 22:213-9.

42. Akdogan M, Ozguner M, Aydin G, Gokalp O. Investigation of biochemical and histopathological effects of Mentha piperita Labiatae and Mentha spicata Labiatae on liver tissue in rats. Hum Exp Toxicol 2004, 23:21-8.

43. Baba S, Osakabe N, Natsume M, Terao J. Orally administered rosmarinic acid is present as the conjugated and/or methylated forms in plasma, and is degraded and metabolized to conjugated forms of caffeic acid, ferulic acid and m-coumaric acid. Life Sci 2004, 75:165-78.

44. Baba S, Osakabe N, Natsume M, Yasuda A, Muto Y, Hiyoshi K, et al. Absorption, metabolism, degradation and urinary excretion of rosmarinic acid after intake of Perilla frutescens extract in humans. Eur J Nutr 2005, 44:1-9.

45. Stalmach A, Steiling H, Williamson G, Crozier A. Bioavailability of chlorogenic acids following acute ingestion of coffee by humans with an ileostomy. Arch Biochem Biophys 2010, 501:98-105.

46. Stalmach A, Mullen W, Barron D, Uchida K, Yokota T, Cavin C, et al. Metabolite profiling of hydroxycinnamate derivatives in plasma and urine after the ingestion of coffee by humans: identification of biomarkers of coffee consumption. Drug Metab Dispos 2009, 37:1749-58.

47. Ono Y, Yamamoto T, Kubo KY, Onozuka M. Occlusion and brain function: mastication as a prevention of cognitive dysfunction. J Oral Rehabil 2010, 37:624-40.

48. Tildesley NT, Kennedy DO, Perry EK, Ballard CG, Savelev S, Wesnes KA, et al. Salvia lavandulaefolia (Spanish sage) enhances memory in healthy young volunteers. Pharmacol Biochem Behav 2003, 75:669-74.

49. Tildesley NT, Kennedy DO, Perry EK, Ballard CG, Wesnes KA, Scholey AB. Positive modulation of mood and cognitive performance following administration of acute doses of Salvia lavandulaefolia essential oil to healthy young volunteers. Physiol Behav 2005, 83:699-709.

50. Kennedy DO, Wake G, Savelev S, Tildesley NT, Perry EK, Wesnes KA, et al. Modulation of mood and cognitive performance following acute administration of single doses of Melissa officinalis (Lemon balm) with human CNS nicotinic and muscarinic receptor-binding properties. Neuropsychopharmacology 2003, 28:1871-81.

51. Mimica-Dukic N, Bozin B, Sokovic M, Mihajlovic B, Matavulj M. Antimicrobial and antioxidant activities of three Mentha species essential oils. Planta Med 2003, 69:413-9.

52. Cuvelier M-E, Richard H, Berset C. Antioxidative activity and phenolic composition of pilot-plant and commercial extracts of sage and rosemary. J Amer Oil Chem Soc 1996, 73:645-52.

53. Zgorka G, Glowniak K. Variation of free phenolic acids in medicinal plants belonging to the Lamiaceae family. J Pharm Biomed Anal 2001, 26:79-87. 
54. Shekarchi M, Hajimehdipoor H, Saeidnia S, Gohari AR, Hamedani MP. Comparative study of rosmarinic acid content in some plants of Labiatae family. Pharmacogn Mag 2012, 8:37-41.

55. Petersen RC, Thomas RG, Grundman M, Bennett D, Doody R, Ferris S, et al. Vitamin E and donepezil for the treatment of mild cognitive impairment. N Engl J Med 2005, 352:2379-88.

56. Doody RS, Ferris SH, Salloway S, Sun Y, Goldman R, Watkins WE, et al. Donepezil treatment of patients with MCI: a 48-week randomized, placebo-controlled trial. Neurology 2009, 72:1555-61.

57. Dastmalchi K, Ollilainen V, Lackman P, Boije af Gennas G, Dorman HJ, Jarvinen PP, et al. Acetylcholinesterase inhibitory guided fractionation of Melissa officinalis L. Bioorg Med Chem 2009, 17:867-71.

58. Mushtaq N, Schmatz R, Pereira LB, Ahmad M, Stefanello N, Vieira JM, et al. Rosmarinic acid prevents lipid peroxidation and increase in acetylcholinesterase activity in brain of streptozotocin-induced diabetic rats. Cell Biochem Funct 2014, 32:287-93.

59. Lee YW, Kim DH, Jeon SJ, Park SJ, Kim JM, Jung JM, et al. Neuroprotective effects of salvianolic acid B on an Abeta25-35 peptide-induced mouse model of Alzheimer's disease. Eur J Pharmacol 2013, 704:70-7.

60. Cropley V, Croft R, Silber B, Neale C, Scholey A, Stough C, et al. Does coffee enriched with chlorogenic acids improve mood and cognition after acute administration in healthy elderly? A pilot study. Psychopharmacology 2012, 219:737-49.

61. Rafnsson SB, Dilis V, Trichopoulou A. Antioxidant nutrients and age-related cognitive decline: a systematic review of population-based cohort studies. Eur J Nutr 2013, 52:1553-67.

62. Blackwell T, Yaffe K, Ancoli-Israel S, Redline S, Ensrud KE, Stefanick ML, et al. Association of sleep characteristics and cognition in older community-dwelling men: the MrOS sleep study. Sleep 2011, 34:1347-56.

63. Blackwell T, Yaffe K, Laffan A, Ancoli-Israel S, Redline S, Ensrud KE, et al. Associations of objectively and subjectively measured sleep quality with subsequent cognitive decline in older community-dwelling men: the MrOS sleep study. Sleep 2014, 37:655-63.

64. An KY, Zakzanis KK, Joordens S. Conducting research with non-clinical healthy undergraduates: does effort play a role in neuropsychological test performance? Arch Clin Neuropsychol 2012, 27:849-57.

65. Schmitt JA, Benton D, Kallus KW. General methodological considerations for the assessment of nutritional influences on human cognitive functions. Eur J Nutr 2005, 44:459-64. 